EDITORIAL

\title{
THE AMERICAN BOARD OF PSYCHIATRY AND NEUROLOGY: AN IMMODEST PROPOSAL FOR CHANGE
}

\author{
STUART C. YUDOFSKY, MD
}

In his essay, "A Modest Proposal," Jonathan Swift proposed that the Irish bolster an economy devastated by English taxation by breeding and marketing their children for culinary consumption. This editorial will conclude with an immodest proposal: that the certification and recertification process of the American Board of Psychiatry and Neurology, Inc. (ABPN) be radically revised.

Dr. Adolf Meyer, in his 1928 Presidential Address before the American Psychiatric Association, proposed that the Association establish professional standards for training and competency in psychiatry. ${ }^{1}$ The ABPN was then formed under the tripatheid authorities of the American Psychiatric Association, the American Neurologic Association and the American Medical Association. ${ }^{2}$ The first certifying examination in American psychiatry was entirely oral and took place on June 7, 1935 at the Philadelphia General Hospital. During the subsequent 45 years the requirements for certification have undergone continuous and significant revision. Among such revisions was the addition of a written multiple choice examination (Part I) which is administered once yearly and proports to test "cognition through recall, interpretation of data, and problem-solving capabilities. ${ }^{3}$ "

The oral portion of the ABPN Examination has recently undergone comprehensive restructuring. In the previous years the candidate was required to interview up to eight patients in the presence of examiners who then evaluated the candidate for 30 minutes for each patient interviewed. Presently, a candidate spends only thirty minutes evaluating a "live" psychiatric patient. The remainder of the so-called "orals" is a videotape of patients with neurological illnesses followed by multiple choice questions and a 30-minute videotape of a patient with a psychiatric illness. Thirty minute oral examinations follow both 
the videotaped and the "live" psychiatric patients. The following paragraph outlines the most frequent and fervent criticisms of the ABPN as they are represented in the psychiatric journals. Please note that it is the strong feeling of this author that the ABPN has been led throughout its history by outstanding, selfless psychiatric educators who have attempted to remedy, where the test structure permitted, the deficiencies noted in the following published criticisms:

\section{Criticisms of the Written Examination}

The Importance of Testmanship. The multiple-choice format under severe time limitations may reflect skillful testmanship more than the psychiatric abilities and knowledge of the candidate. ${ }^{4}$

The Uncertain Emphasis. The candidates are uncertain about the degree of emphasis to place on such topics as psychiatric history, legal psychiatry, community psychiatry, etc. There may be a tendency to over prepare in esoteric areas and neglect areas of broad clinical import.

The Questionable Validity of a Written Test. The candidate proficient in retaining and remitting factual data for a written test may lack the interpersonal skills to elicit the requisite information from a "live patient;" perhaps lacking may even be the more human qualities and motivations essential for the effective therapeutic dealings with patients.

\section{Criticism of the Oral Examination.}

Poor reliability of the oral examination. Included in this category are: (a) "The luck of the patient draw." The advantage of a highly verbal and cooperative patient with a clearly-defined relatively common psychiatric illness, as opposed to the uncooperative patient with vague complaints and a rare illness is manifest; ${ }^{5}$ and (b) The luck of the examiner draw. Many candidates feel that their age, race, countries of origin, and particularly their philosophical bent in psychiatry works against them in their orals. In preparation for the oral boards a candidate is often advised to "diagnose" the examiner-whether he/she is biologically, dynamically, behaviorally, etc. oriented, and to adjust the interview and answers to questions accordingly. ${ }^{6}$ 
The importance of testmanship. According to Dr. Alan Morgenstern's "A Criticism of Psychiatry's Board Examinations," the capacity to deal with stress is an important artifact ..." The lucky candidate "plays the game well because he is bright, fluent, and sensitive to cues... he understands his examiners' image of the 'good psychiatrist' and acts accordingly." 7

The Questionable Qualifications of the Examiners. Are the examiners versed in the vast literature on assessment of clinical skills? Do they have personal biases? How well are they selected and prepared for testing candidates ${ }^{8,9}$.

The High Failure Rate of the Oral Examination. Of those candidates who took Part II of their orals in 1977, less than $60 \%$ was successful, in 1978 , less than $65 \%$ was successful. This figure is highly representative of the passing rate throughout the years in which oral examinations have been given ${ }^{2}$.

The Adverse Emotional Reactions of Those Who Fail. Dr. Martin R. Lipp ("Experiences of Psychiatry Board Exam Casualties: A Survey Report") collected completed questionnaires of 52 psychiatrists who failed to pass the test of the ABPN on their first try. He reported that, "all of the respondents experienced depression ... for many shame, bitterness, anger, bewilderment, helplessness, and frustration were important themes that dominated their lives for months or years after learning their exam results ... several casualties blamed their Board experience for major repercussions in their private life."

The Oral Examination Per Se Is Not a Learning Experience. Responding to voluminous criticism, the ABPN now provides feedback on examination performance to those who fail Part II. There is no spontaneous feedback during the examination or follow-ups of the case material presented. To this date there has not been systematic feedback to training directors regarding the performance of their graduates on the examination.

Little Therapeutic Benefit to Patient Volunteers. Over two thousand patients yearly volunteer to be examined by the candidates for certification. To the knowledge of the author, the interview by the candidate is not integrated into the overall therapeutic regimen of these patients. 


\section{THE IMMODEST PROPOSAL FOR CHANGE}

Physicians who have taken in their lifetimes National Merit Examinations, College Board Entrance Examinations, Medical College Admission Tests, and National Board of Medical Examiners' Tests will not tolerate the capricious reliability of the current oral examinations for Board certification in psychiatry. It is for this reason that Part II has, in the past three years, been revised so that two thirds of this so-called "oral examination" is now, in actual application, an elaborate written examination with video tape and multiple choice format. We psychiatrists must ask ourselves if we now, for the purposes of test reliability, assess professional competence by methods which we ourselves do not believe to be valid. Do we psychiatrists actually feel that the safe competence of a psychiatric practitioner can be judiciously gauged without the benefit of observing the clinician/candidate in diagnostic and therapeutic contact with live patients?

Secondly, we psychiatrists should question if it is likely that governmental agencies and consumer groups will demand more objective measurements of continuing professional competence (recertification) than the voluntary attendance by psychiatrists at educational seminars or the voluntary taking and utilization of self-assessment tests.

It is therefore that this paper proposes the following restructuring of the certifying procedure of the ABPN. Central to the certification and recertification structure advocated by this paper would be the creation of four to five clinical facilities which, let us call, National Centers for Patient Treatment and Professional Assessment. In overall structure the Centers will appear and function in similar fashion to that of any university training program of high quality with the following exception: each faculty member would have thorough and special training in the testing and assessment of professional skills and competence. The house staff of these Centers would be candidates for certification and recertification. They would be the primary care physicians as well as the specialists for the patient population-both inpatient and outpatient-served by the Centers. Each candidate would spend one week at a Center and evaluate and treat patients under the supervision and scrutiny of the faculty. Certification candidates would be required to pass a written test prior to their admission to the Centers. Candidates for recertification would not be required to pass a written examination before their week of assessment at the Centers. Such candidates would also be provided the opportunity to be reassessed primarily in areas of their subspecialty interests. The Centers would have available ongoing seminars as well as video tape 
educational facilities to provide review courses in the latest advances in the field.

Inherent to this system would be the following advantages:

1. The candidates would be evaluated in a "real life clinical setting" in which they would be diagnosing and treating patients with immediate and relevant medical needs.

2. The "luck of the draw" frailty of the current system of oral examination would be obviated by candidates who would see many patients over the course of several days (five hours per day, for six days as opposed to thirty minutes in the current system).

3. Multiple Board examiners with special training in reliable assessment and evaluation of professional competence would have the opportunity to observe the candidates over their week of stay at the Center.

4. The Board examiners will be allotted adequate time to discuss and assess candidates with the additional advantage of large samples of candidates for more judicious comparisons.

5. The Facilities would provide a permanent structure and an ideal laboratory for collecting and collating data regarding training; and could thereby serve as a vital resource for the evaluation of training programs.

6. The level of stress in the competent candidate would likely be reduced. Fears over the vicissitudes of a single uncooperative patient or of a biased examiner would be reduced. Because the candidate would see many patients in need of help and would be evaluated by several examiners, there would be less of the need to cram for esoterica. The candidate would not have a pressured feeling that he/she would have to show all that he/she knows in one hour.

7. Testmanship seemingly would have less of an impact in a prolonged demonstration of clinical capacity. The advantages of verbal facility and the ability to make an initial positive impression would be less of a factor in an experience which extends many hours over the course of an entire week.

8. The Centers could provide valuable educational opportunity for candidates. For example, rather than failing a motivated candidate with deficient knowledge in a specific area, the deficiency could be detected early in the week of evaluation and corrected by specially designed educational emphasis.

9. Important screening functions could be provided. Candidates with physical or psychological conditions which impair clinical compe- 
tence could be better identified in a format which allotted more time for assessment. Such candidates could be encouraged to seek or even be provided with corrective therapeutic opportunities.

10. The permanent structure of the Centers with acknowledged experts in evaluation and assessment could be granted the requisite authority to protect the public from candidates assessed as incompetent or destructive.

11. Biases in the clinical emphasis of examiners would be reduced. Political checks and balances would be inherent in the organization and administration of the Center. For example, key positions in the Centers such as directors of professional assessment, clinical services, research, and education would be selected by multispecialty search committees within the Centers themselves, and would be subject to ratification by designated committees of the APA, the ABPN, the AMA, as well as representatives of the patient population served. Questions over the placement of emphasis in the clinical knowledge and skill required for certification would be subject to discussions in the open fora of professional meetings, journals, newsletters, etc. and not subject to the present vagaries of the individual examiners.

12. The large number of candidates inherent in a cohesive recertification program could be handled by the structure proposed. Each Center could evaluate a maximum of 1500 candidates per year if the facility were similar in structure to a ten resident per year residency training program. Thus, with a six year recertification process, a maximum population of 9,000 psychiatrists could be accomodated by a single Center.

13. The Centers are financially feasible. The Centers could be converted from existing facilities which serve a particular patient population, or be referral centers for the evaluation of specific disease entities. Funding for the Centers would be provided by third party payment sources for the clinical care provided, from research stipends, from teaching fees, and from the very consumer and governmental groups who advocate certification and recertification. Certainly National Centers for Treatment and Professional Assessment would be no less deserving of federal funding than V.A. hospitals, Public Health Service hospitals, or medical centers for the military. In conclusion, it is hoped that the structure advocated in this paper will provide an instrument to assess professional competence in psychiatry which is valid, reliable, and, above all, humane to patient, candidate, and examiner. 


\section{REFERENCES}

1. Meyer, A.: Thirty-five years of psychiatry in the United States and our present outlook. American Journal of Psychiatry 84:1-31, 1928.

2. Freeman, E., Ebaugh, E. G., Boyd, D. A. Jr.: The founding of the American Board of Psychiatry and Neurology, Inc. American Journal of Psychiatry 115:769-777, 1959.

3. Small, S. M.: Focus continuing certification in psychiatry. Journal of Psychiatric Education 2:4-13, 1978.

4. Morgenstern, A. L.: A systematic approach for oral board examinations in psychiatry. American Journal of Psychiatry 129:86-90, 1972.

5. Lipp, M. R.: Experiences of psychiatry board exam casualties: A survey report. American Journal of Psychiatry 133:279-283, 1976.

6. Congram, G. P.: On the boards again. American Journal of Psychiatry 133:718, 1976.

7. Morgenstern, A. L.: A criticism of psychiatry's board examinations. American Journal of Psychiatry 127:73-80, 1970.

8. Napoliello, M. J.: From board candidate to rookie examiner. American Journal of Psychiatry 134:1264-1269, 1977.

9. Lipp, M. F.: American Journal of Psychiatry 133:1207-1208, 1976. 